\title{
O Curso de Licenciatura Intercultural para a Educação Básica Indígena no Estado do Maranhão
}

\author{
Aldir Santos de Paula ${ }^{1}$ \\ Marivania Leonor Souza Furtado ${ }^{2}$
}

\section{RESUMO}

No Brasil, a relação entre os povos indígenas e o colonizador sempre foi conflituosa, tanto no plano físico quanto no plano simbólico. Embora interligadas, os conflitos no plano simbólico acarreta(ra)m a destituição de práticas sociais diversificadas, por meio, mas não exclusivamente, da catequese e da escolarização nos moldes não-indígenas, tendo em vista que o paradigma assimilacionista, que pautou as relações entre povos indígenas e o poder central, perdurou por quase quatrocentos anos, e foi seguido pelo paradigma integracionista, implementado pelos órgãos oficiais de tutela. A mudança deste paradigma só foi possível com a Constituição Federal, de 1988, e mais tarde com a Lei de Diretrizes e Bases da Educação Nacional (LDB), de 1996, que asseguraram os princípios da educação diferenciada para os povos indígenas e as competências para a oferta da educação escolar bilíngue e intercultural, com vistas a fortalecer as práticas socioculturais e a diversidade linguística dos povos indígenas. Este trabalho tem como objetivo apresentar a experiência do Curso de Licenciatura Intercultural proposto pela Universidade Estadual do Maranhão, que, entre alguns de seus objetivos formais, intenciona reverter o quadro deficitário de docentes indígenas atuando nas escolas indígenas, além de garantir o acesso desses povos aos conhecimentos universais acumulados.

PALAVRAS-CHAVE: Educação escolar indígena. Povos indígenas no Maranhão. Formação universitária. UEMA.

1 Doutor em Linguística pela Universidade Estadual de Campinas (Unicamp). Professor da Faculdade de Letras da UFAL (FALE - UFAL). Maceió, AL, Brasil. E-mail: apu@uol.com.br.

2 Doutora em Geografia, área Produção Social do Espaço pela Universidade Estadual Paulista - Campus Presidente Prudente. Professora do Departamento de Ciências Sociais Aplicadas (DCS/CCSA - UEMA). São Luís, MA, Brasil. E-mail: dcsuema@yahoo.com.br. 


\section{ABSTRACT}

In Brazil, the relationship between indigenous peoples and the colonizer has always been conflicting, both physically and symbolically. Although interrelated, conflicts on the symbolic plane bring about the removal of diverse social practices, through, but not exclusively, catechesis and nonindigenous schooling, in view of the fact that the assimilationist paradigm, which guided the relations between indigenous peoples and the central power, lasted for almost four hundred years, and was followed by the integrationist paradigm, implemented by the SPI. The change of this paradigm was only possible with the Federal Constitution of 1988 and later with the LDB (Law of Guidelines and Bases of National Education) of 1996, which ensured the principles of differentiated education for indigenous peoples and the provision of bilingual and intercultural school education, with a view to strengthening socio-cultural practices and the linguistic diversity of indigenous peoples. This work aims to present the experience of the Intercultural Licentiate Course proposed by the State University of Maranhão, which, among some of its formal objectives, intends to reverse the deficit of indigenous teachers working in indigenous schools, besides guaranteeing the access of these people to cumulative universal knowledge.

KEYWORDS: Indigenous school education. Indigenous peoples in Maranhão. University education. UEMA.

\section{Introdução}

A diversidade etnolinguística brasileira é significativa, quando comparada a outros países ou mesmo a outras regiões do planeta. Ainda assim, grande parte dessas línguas encontra-se ameaçada frente à língua majoritária, mesmo aquelas que possuem uma população acima de trinta mil falantes, o que não é comum em termos populacionais, tendo em vista que, distribuídos no vasto território do Brasil, existem muitos povos e línguas com poucos falantes.

Se, por um lado, existem povos considerados monolíngues em língua indígena, por outro, a maioria dos povos indígenas no Brasil vivencia graus variados de bilinguismo, derivado das diferentes formas de contato com a sociedade nacional e ainda existem povos 
monolíngues em língua portuguesa. Desta forma, o monolinguismo em língua indígena, em certa medida, é a fase anterior ao bilinguismo, que é seguida pelo monolinguismo em língua portuguesa, que, neste cenário, poderia ser caracterizado como o ápice do processo glotocida engatilhado há cerca de quinhentos anos, com a chegada dos colonizadores europeus.

Atualmente, dos vinte e sete povos indígenas no Nordeste, apenas sete falam suas línguas originárias, um em Pernambuco, os Fulni-ô, que falam o Yaathê, e os demais no Maranhão, como será explicitado adiante, em uma população de mais de duzentos mil índios (IBGE, 2010), o que aponta para cerca de vinte povos indígenas que não empregam a língua autóctone funcionalmente em seus cotidianos. Nessa região, a diversidade linguística, portanto, foi profundamente afetada, não restando, para muitos desses povos, sequer registros ou informações, mesmo que imprecisos, sobre suas línguas. Embora, esse quadro de perda linguística não seja vivenciado exclusivamente na região nordeste do Brasil, nesta região, o grau do prejuízo é agudo; em outras regiões, entretanto, por conta ou da colonização tardia e/ou dos processos de produção recentemente incorporados à perda linguística, já pode ser sentida, especialmente, entre os povos que têm a transmissão linguística intergeracional prejudicada pela entrada progressiva da língua portuguesa.

Diante desse contexto de insegurança linguística, o papel da escola nas aldeias precisa levar em consideração esses aspectos. Dessa forma, a qualificação dos próprios indígenas como condutores de todo o processo de ensino aprendizagem nas aldeias deve ser prioridade dos órgãos públicos afetados pela demanda por educação escolar indígena.

Este artigo apresentará a experiência de um Curso de Licenciatura Intercultural proposto pela Universidade Estadual do Maranhão que apresenta, como um dos objetivos formais, reverter o quadro deficitário de docentes indígenas atuando nas escolas indígenas. Para tal, está dividido em três seções. A primeira, após esta apresentação, discute a configuração histórica e legal na qual se pauta a educação escolar indígena. Em seguida, faremos uma breve apresentação dos povos indígenas no Maranhão enfatizando os aspectos educacionais entre esses povos. E, por fim, discorreremos sobre a estrutura e funcionamento do curso de formação de professores indígenas sobre o qual apresentaremos uma abordagem crítica. 


\section{Antecedentes históricos e legais}

De uma perspectiva histórica, com viés tradicional, a chegada dos europeus protagoniza acontecimentos, especialmente a partir do segundo quartel do século XVI, que resultará no estabelecimento de um estado, que se caracterizaria como brasileiro apenas quatro séculos adiante.

No período colonial, como habitantes originários do território, os povos indígenas, especialmente os do litoral, embora considerados como elementos marginais, foram os primeiros alvos do processo 'civilizatório' do estado português.

Ainda no período colonial, os povos indígenas foram se convertendo, de acordo com as circunstâncias e os objetivos do colonizador, de parceiros comerciais, nos primeiros contatos, para, em seguida, a mão de obra para a exploração dos recursos naturais ou ainda para as construções militares e/ou civis nos núcleos urbanos iniciais. Ainda nesta segunda etapa, foram alvos do processo de catequese, empreendido pelas ordens religiosas católicas.

Concomitantemente, a expropriação fundiária e a exploração da força de trabalho dos povos indígenas processam-se o quadro de expropriação linguística, o que ocasiona uma permanente, mas não pacífica, relação com a sociedade nacional, que nega os elementos de identidade cultural desses povos e os descaracteriza como povos originários.

Dessa forma, como consequência dos séculos de relação assimétrica de contato, muitos povos indígenas se assimilaram completamente e se voltaram, pelos mais variados motivos, inclusive pela violência, para a vida brasileira, enquanto outros povos, mesmo tendo que reconfigurar suas pertenças e aspectos simbólicos próprios mantiveram suas identidades indígenas e se reconhecem e/ou são reconhecidos como povos indígenas diferenciados da sociedade nacional.

Tal violência ocorre não apenas no plano físico, a partir da intensa dizimação dos povos indígenas no Brasil, seja por conflitos ou guerras, seja por doenças trazidas pelos colonizadores, ou ainda pelas novas formas de ordenamento territorial distanciadas das dinâmicas adotadas pelos povos indígenas, mas também no plano simbólico, como a destituição de práticas sociais diversificadas, por meio, mas não exclusivamente, da catequese e da escolarização nos moldes não indígenas. 
Este paradigma assimilacionista, que pautou as relações entre povos indígenas e o poder central, perdurou por quase quatrocentos anos, e foi substituído pelo paradigma integracionista implementado pelos órgãos oficiais de tutela, com a criação do Serviço de Proteção ao Índio (SPI). Ao ser extinto, o SPI cede lugar à Fundação Nacional do Índio (FUNAI), que, em 1973, estabelece o Estatuto do Índio, que tinha como propósito "integrar os índios à sociedade brasileira, assimilando-se de forma harmoniosa e progressiva" (ARAÚJO, 2006, p. 34). De forma geral, esta Lei não garante cidadania plena aos índios, o que implica em dizer que os índios não podem se autorrepresentar ou legislar, devendo ser tutelados pelo Estado.

Nessa linha histórica, somente a partir da Constituição Federal de 1988 que, juridicamente falando, os povos indígenas ganham novas possibilidades de articulação. Para Araújo (2006, p. 38), “a constituição de 1988 trouxe uma série de inovações no tratamento da questão indígena (...) indicando novos parâmetros para a relação do Estado e da sociedade brasileira com os índios (...) uma espécie de marco divisor para a avaliação da situação dos índios no Brasil”. Dessa forma, ficam assegurados os direitos permanentes e coletivos dos índios, de suas comunidades e organizações como ferramenta de defesa de seus direitos. Os povos indígenas, então, deixam de ser vistos pelo Estado brasileiro como objetos do processo civilizatório brasileiro, sendo reconhecidos como sujeitos destes.

Com base na Constituição Federal, de 1988, e na Lei de Diretrizes e Bases da Educação Nacional, de 1996, que asseguram os princípios da educação diferenciada para os povos indígenas e as competências para a oferta da educação escolar bilíngue e intercultural, com vistas a fortalecer as práticas socioculturais e a diversidade linguística dos povos indígenas, além de garantir o acesso desses povos aos conhecimentos universais acumulados, e a partir da demanda apresentada pelo movimento indígena em diversos fóruns, surge à necessidade de um curso de formação de professores em nível superior no Maranhão que se propõe a atender a realidade específica e diferenciada dos povos indígenas desse Estado. 


\section{Os povos e as línguas indígenas no estado do Maranhão}

Atualmente, no estado do Maranhão são identificados, oficialmente, nove povos indígenas cuja população total é de mais de trinta mil pessoas (IBGE, 2010), distribuídas em duzentas e oitenta aldeias, localizadas em dezesseis terras indígenas situadas em dezoito municípios maranhenses e estão agrupados em dois troncos linguísticos: Macro-Jê e Tupi, como pode ser visto em seguida:

Quadro I - Distribuição das línguas indígenas por tronco linguístico.

\begin{tabular}{|l|l|}
\hline \multicolumn{1}{|c|}{ Macro-Jêe } & \multicolumn{1}{c|}{ Tupi } \\
\hline Apaniekrá (Canela) & Awá (Guajá) \\
\hline Krenyê & Kaapor \\
\hline Krepu'kateyé & Tenetehar (Guajajara) \\
\hline Krikati & \\
\hline Pukobyê (Gavião) & \\
\hline Ramkokamekrá & \\
\hline
\end{tabular}

Fonte: Os/as autores/as.

A diversidade entre os povos se manifesta tanto nos aspectos linguísticos quanto na forma de organização política, social, econômica e nas manifestações simbólicas e rituais. Cada povo desenvolve formas próprias de contato, configurando assim específicas situações históricas de contato interétnico. Deste quadro, destacamos, por exemplo, os Tentehar, com mais de trezentos anos de contato, e os Awá/Guajá, com menos de meio século de contato com a sociedade majoritária.

Com isso, as situações de contato têm determinado a forma como os processos de escolarização se manifestam em suas respectivas aldeias. Os povos de contato mais duradouro e intermitente são, em sua maioria, bilíngues e reivindicam a escolarização em todos os níveis. No outro lado do espectro, encontram-se os Awá/Guajá, que, em sua maioria, falam somente a língua indígena e ainda não assumem integralmente os processos de escolarização em suas aldeias.

Os Awá formam uma das últimas sociedades que utilizam, como prática econômica predominante, a caça de animais e a coleta de frutos encontrados no território, que possui uma área total de 702.887 ha, entre a Terra Indígena Alto Turiaçu até a Terra Indígena Caru. 
Este povo indígena tem apenas uma escola funcionando, com 39 alunos matriculados, todos na segunda etapa do ensino fundamental $\left(6^{\circ}\right.$ a $9^{\circ}$ anos). Nessa escola, atua somente um professor não indígena. Embora representem uma parcela expressiva da diversidade sociolinguística e cultural no Maranhão, os Awá-Guajá ainda não demandam por formação de nível superior e, portanto, não participam do Projeto em tela.

O povo Kaapor habita a terra indígena Alto Turiaçu, demarcada com 530.000 ha. e são habitantes da pré-amazônia maranhense. Constroem sua territorialidade de acordo com esse ecossistema e orientam suas atividades por um calendário definido pelos ciclos da natureza, assim como sua mitologia é elaborada a partir da floresta. Devido a esse fator, mantêm uma distância sociocultural e linguística bastante acentuada em relação à sociedade envolvente. Os indivíduos são todos falantes de sua língua indígena e poucos desenvolvem o bilinguismo.

Estão instaladas e em funcionamento doze escolas com mais de quinhentos e cinquenta alunos matriculados. O quadro docente atuante é composto por trinta e dois professores contratados pela SEDUC, sendo vinte e cinco indígenas e os demais não indígenas. A atuação desses professores restringe-se às etapas iniciais do ensino fundamental, devido à falta de formação dos docentes em nível superior. Além da formação restrita dos docentes, a escola também não conta com materiais didático-pedagógicos específicos à realidade do povo.

Os Tenetehar, povo indígena mais numeroso do Maranhão, iniciaram suas experiências escolares ainda com as missões jesuíticas, no século XVII e capuchinhas, a partir do século XIX. Atualmente, estão distribuídos em dez terras indígenas, que se localizam em vários municípios do Maranhão, principalmente às margens dos rios Corda, Mearim e Pindaré. Encontram-se também no Pará, às margens dos rios Gurupi, Guamá e Capim. Os do Maranhão são conhecidos regionalmente como Guajajara e os do Pará, como Tembé. No entanto, compartilham as mesmas características socioculturais e linguísticas, apesar de identificarem-se como povos distintos. Os Tenetehar estão em contato com a sociedade envolvente desde os primeiros tempos da colonização.

A reprodução material dos Tenetehar é obtida, basicamente, pela agricultura. Próximos a cada aldeia existem os "centros", que são abrigos temporários localizados junto às roças e onde, 
geralmente, estão instaladas as casas de farinha. A caça é uma atividade mais esporádica por estar escassa. Praticam também a pesca principalmente os que vivem em aldeias próximas a rios ou igarapés.

O povo Tenetehar possui duzentos e quarenta e quatro escolas, com um quantitativo de mais de doze mil estudantes matriculados. O número de professores que atende a essa demanda é de setecentos e noventa e um, sendo que trezentos e quarenta e sete destes são indígenas e os demais, não indígenas.

A prática de ensino bilíngue é restrita a algumas aldeias. Esse fato é determinado pela ausência de material didático específico e falta de formação docente para o exercício do magistério indígena.

Os Apaniekrá habitam uma única aldeia na Terra Indígena Porquinhos, demarcada com 79.520 hectares. Outro grupo também chamado pelos regionais de Canela são os Ramkokamekrá, que se localizam na área Indígena Canela, com 125.212 hectares. Mesmo sendo confundidos, os Apaniekrá se definem como distintos dos Ramkokamekrá.

Como os demais povos falantes de língua do tronco MacroJê, os Apaniekrá também distribuem suas casas na aldeia formando um círculo. Estão em contato com segmentos da sociedade nacional desde o século XIX e estiveram envolvidos em diversos conflitos com criadores de gado, fato comum na história dos povos de língua Macro-Jê, no Maranhão.

Para a sua reprodução material, praticam a agricultura, a pesca e o extrativismo, além de fabricar cestarias como obras de arte e as vendem como artesanato.

Os Apaniekrá praticam a corrida com tora e outros jogos próprios do povo e jogos interculturais, fazem os rituais de passagens e participam das festas dos parentes das outras etnias.

No território dos Apaniekrá, existe uma escola em funcionamento, que tem matriculados cento e cinquenta e nove estudantes e doze professores, sendo oito indígenas e quatro não indígenas.

Os Krenyê tiveram os primeiros contatos com a sociedade nacional através de forças militares, no final do século XVII, mas, apenas durante a última década do século XVIII, efetivamente, ocorreram incursões contra sua população e seu modo de vida.

A terra tradicional desse povo era localizada no Baixo Rio Mearim, uma das portas de entrada do processo de colonização do 
Maranhão. Vivia na antiga aldeia Mangueira, localizada na região conhecida como distrito Pedra do Salgado, no município de Bacabal - MA.

Por volta de 1960, os últimos Krenyê, sobreviventes de uma epidemia de sarampo e encurralados por fazendeiros vindos do Ceará, foram, por orientação do SPI, obrigados a se mudar para a Terra Indígena Pindaré, do Povo Tentehar. Viveram entre este povo até a década de 1990, quando um grupo decidiu viver na Terra Indígena Governador, dos Pukobyê-Gavião, município de Amarante do Maranhão.

Durante todo esse tempo, o povo foi considerado extinto. Em 2003, começam a luta pelo reconhecimento étnico, que foi conquistado em 2009. Atualmente, parte desse povo vive na periferia de Barra do Corda, aguardando o cumprimento de decisão judicial da Ação Civil Pública, impetrada pelo Ministério Público Federal para compra de uma terra.

Os Krenyê possuem uma escola em seu território, com dezenove estudantes matriculados e apenas um professor não indígena.

Os Krikati habitam um território, parcialmente demarcado em 1997, e já homologado, com cento e quarenta e cinco mil hectares, localizados nos municípios de Montes Altos, Amarante, Sítio Novo e Lajeado Novo.

A população Krikati é de mais de setecentas pessoas que se dividem em aldeias situadas basicamente às margens da rodovia MA 280. Os primeiros contatos dos Krikati com a sociedade nacional apontam para meados do século passado, por volta de 1848, quando foi fundada a colônia militar de Santa Tereza, atual cidade de Imperatriz. Dessa forma, a situação histórica de contato desse povo é de quase dois séculos.

No território dos Krikati, existem cinco escolas em funcionamento, onde estão matriculados trezentos e dezesseis estudantes e atuam trinta e um professores, dos quais vinte são indígenas e onze não indígenas. Os professores Krikati atuam prioritariamente nas primeiras etapas do ensino fundamental e lecionam a língua indígena em toda a educação básica nas aldeias.

Os Pukobyê são conhecidos regionalmente por Gavião e têm uma população de mais de setecentas pessoas. Segundo Reis (1996 apud FURTADO, 2012), os Pukobyê foram um dos povos que mais resistiram aos processos de colonização implementados, devido à 
sua localização geográfica, situada numa área denominada Fronteira, por ser "espaços incultos e despovoados em razão de numerosas povoações bárbaras e indomésticas que neles se observam”.

Até o final de 1960, os Pukobyê estavam distribuídos entre as aldeias Governador, Riachinho, Rubiácea e São Félix. Dez anos depois, estavam praticamente agrupados na aldeia Governador, cujo território demarcado leva o mesmo nome.

A Terra Indígena Governador situa-se no município de Amarante e foi demarcada, em 1978, com trinta mil e novecentos hectares. Esta área é cortada por uma rodovia municipal que liga Amarante à estrada MA 006, o que permite o contato permanente dos Pukobyê com os regionais e a sede do município de Amarante, bem como favorece o deslocamento frequente para Imperatriz, sede regional da administração da FUNAI e da SEDUC.

Existem seis escolas no território dos Pukobyê, que atendem mais de trezentos estudantes e onde atuam trinta e cinco professores, dos quais dezoito são indígenas.

Tanto os Pukobyê quanto os Apaniekrá têm participado de projetos educacionais desenvolvidos pelo CTI, como também atualmente pelo Instituto Federal de Educação Tecnológica do Maranhão (IFMA), de Barra do Corda, que tem realizado cursos profissionalizantes em parceria com a FUNAI, para atender às demandas específicas desses povos, o que tem resultado em práticas interculturais consequentes de gestão dos territórios em setores específicos.

Os Ramkokamekrá habitam a terra indígena Canela, atualmente pertencente ao município de Fernando Falcão - MA, em uma aldeia de formato circular, chamada aldeia do Ponto ou Escalvado. Além dessa aldeia sede, existem outras menores, construídas perto das roças, as quais moram no grande período das atividades de agricultura.

Devido ao relativo isolamento dos centros populacionais, este povo mantém suas tradições, crenças e costumes ainda muito fortes. No território Ramkokamekrá, existem duas escolas em funcionamento, que têm setecentos e trinta e cinco estudantes matriculados e onde atuam vinte e oito professores, dos quais treze não são indígenas.

De modo geral, considerando os povos Tupi e Macro-Jê, podemos afirmar que, em sua maioria, os professores desses povos não têm material didático específico para o ensino das línguas 
indígenas, em particular, e de outros materiais no geral. Outro traço comum entre estas escolas é a presença de professores não indígenas assumindo o processo escolar, que é bastante relevante, pois os professores indígenas dedicam-se, preferencialmente, ao ensino da primeira etapa do nível fundamental, enquanto as etapas subsequentes ficam sob a orientação de professores não indígenas contratados pelos municípios próximos, o que, além de contrariar os preceitos normativos e formativos da educação escolar indígena, aponta para a necessidade urgente de formação de professores indígenas para as diversas áreas de formação do ensino fundamental e médio.

\section{3. $O$ curso de formação e sua estrutura}

O Curso de Licenciatura Intercultural para a Educação Básica Indígena, doravante CLINTEBASI, proposto e executado pelo Centro de Ciências Sociais da Universidade Estadual do Maranhão, tem, como público-alvo, indígenas que já atuam como docentes em suas aldeias e para os quais disponibilizaram-se noventa vagas preenchidas por meio de um processo seletivo específico e diferenciado.

O CLINTEBASI objetiva formar professores indígenas em Licenciatura Intercultural, nas áreas das Ciências da Natureza, Ciências Humanas e Ciências da Linguagem, além de procurar preencher uma necessidade da maioria dos povos, como já descrito, pretende ainda possibilitar a produção de material didático específico e diferenciado, visando à garantia da autonomia político-pedagógica das escolas indígenas. Desta forma, o curso objetiva também criar condições teórico-metodológicas e práticas para que os professores indígenas possam se tornar agentes efetivos na construção e reflexão do projeto político-pedagógico, planejamento e gestão da escola em que atuam.

Além de outros objetivos explicitados no projeto, com a formação de professores indígenas será possível estabelecer uma equidade numérica e, quando possível, a ampliação do número de professores indígenas em relação ao de não indígenas, atuando na Educação Básica Indígena, revertendo tanto o atual quadro de 
desigualdade quanto a participação dos indígenas atuando nas escolas de suas aldeias. ${ }^{3}$

Com base na modalidade "parcelada" ou de "alternância" no desenvolvimento de suas atividades, o CLINTEBASI é composto por dois blocos. O Bloco I ou Núcleo Comum tem duração de 3 etapas de Tempo Universidade e 3 Etapas de Tempo Comunidade, com matriz referencial curricular para todos os acadêmicos e o Bloco II ou Núcleo Específico, com duração de sete etapas de Tempo Universidade e a mesma quantidade de Tempos Comunidade. O Curso está organizado nos três grandes temas referenciais de saberes especializados: Línguas e saberes sobre o mundo físico, da vida e quantificações interculturais (Área das Ciências da Natureza); Línguas e saberes sobre o movimento das sociedades no espaço (Área das Ciências Humanas) e Línguas indígenas em interação com Línguas Oficiais (área das Ciências da Linguagem).

Em cumprimento à modalidade da Pedagogia da Alternância, o CLINTEBASI será realizado em dois tempos: Tempo Universidade (TU) e Tempo Comunidade (TC). No TU, os professores indígenas, preferencialmente, mas não exclusivamente no campus da UEMA - São Luís, estudam em regime de caráter intensivo, presencial e coletivo previstos no desenho Curricular do Curso sob a coordenação dos docentes do curso. Essas etapas devem acontecer, prioritariamente, nos meses de janeiro, fevereiro e julho, atendendo ao princípio da formação em serviço dos professores cursistas, tendo em vista que, nestes meses, em média, as escolas indígenas estão em recesso. Nessas etapas longas, desenvolvem-se os conteúdos previstos no componente curricular bem como é o espaço de articulações políticas dos professores indígenas e de socialização de suas práticas culturais.

$\mathrm{O}$ TC corresponde às etapas que ocorrem no interior de cada aldeia, envolvendo monitores e cursistas, denominadas Atividades Acompanhadas I (Práticas Pedagógicas) e Atividades Acompanhadas II (Carga Horária Complementar dos Componentes Curriculares das partes específicas do Bloco II), além do Estágio Supervisionado, dos Estudos Individuais e de algumas atividades a serem relacionadas como Atividades Complementares.

3 Atualmente, conforme dados da SEDUC, temos mais de mil docentes atuando nas escolas das aldeias, destes mais de $50 \%$ não são indígenas. 
Este período de atividades pedagógicas é mais individualizado, quando o cursista tira suas dúvidas, aprofunda conteúdos, analisa situações particulares, planeja e revisa ações pedagógicas das suas escolas, em alguns períodos, por um monitor e/ou bolsista integrante da equipe de formadores do Projeto.

Parte das Atividades Complementares pode acontecer no interior dos próprios territórios indígenas nos quais se realizam Encontros Pedagógicos e/ou Políticos nos quais os cursistas estejam diretamente envolvidos, promovidos pelas organizações indígenas e ou oficiais que tenham caráter científico, cultural e ou político/ pedagógico e devem ser comprovadas com declarações e certificados apresentados à Secretaria Acadêmica do Curso.

$\mathrm{Na}$ formatação do percurso escolar a ser vivenciado, a articulação do curso em TU e TC coloca-se como fundamental para o desenvolvimento do projeto que visa à formação em serviço dos seus integrantes, respeitando e valorizando os saberes e as realidades dos povos envolvidos no processo de formação.

OCLINTEBASI deve possibilitar o fortalecimento das línguas, tradições e visões de mundo de cada povo e tem a interculturalidade como princípio norteador de todas as relações de formação e atuação da docência indígena. Desta forma, os componentes curriculares devem contribuir para que os professores indígenas sejam inseridos nos contextos de trabalho dentro e fora das aldeias.

\section{Conclusão}

Ainda em fase de execução, já foram realizadas todas as etapas do Bloco de Formação Comum e iniciou-se em janeiro de 2018 a formação específica. Os discentes selecionaram, por auto indicação as áreas de formação específica, ficando o CLINTEBASI assim dividido: 15 alunos na turma de Ciências da Natureza, 25 em Ciências Humanas e 32 em Ciências da Linguagem. A maior procura pela área de Ciências da Linguagem demonstra a preocupação dos cursistas com a situação sociolinguística de seus povos e a relação que a escola poderia favorecer quanto ao prestígio das línguas indígenas, assim assumida pelos próprios falantes.

A segunda maior procura pela área de Ciências Humanas pode ser entendida como a expectativa de que os discentes além de professores em suas aldeias desenvolvem papeis de lideranças 
e representatividade das demandas de seus povos frente aos canais administrativos e, para isso, estão se apropriando dos saberes proporcionados pelas discussões sociológicas, antropológicas, histórico-geográficas, dentre outras.

A menor procura pela Ciência da Natureza reproduz no contexto da educação escolar indígena a dificuldade de formação de professores para essa área do ensino básico.

Do ponto de vista crítico, o CLINTEBASI pode ser analisado sob dois principais aspectos. Inicialmente, tomando como pressuposto a demanda reprimida por formação de nível superior para indígenas atuarem especificamente no magistério em suas aldeias, verificamos que o Curso se mostra como uma grande conquista do movimento indígena. Por outro lado, o grande desafio seria a efetivação do princípio da interculturalidade ir além do aspecto funcional, como é o que de fato ocorre, por ser uma proposta formalizada e implementada visando à inserção dos docentes na carreira do magistério que já está delimitada pelo Estado. Ainda temos a barreira das expectativas dos discentes em serem "funcionários públicos" e não, necessariamente, sujeitos críticos de um processo neocolonial que os seduz.

Dessa forma, o CLINTEBASI, enquanto processo, poderia ser entendido como passos iniciais para se efetivar uma sociedade mais plural, com uma presença indígena reconhecida e valorizada. Enquanto processo formativo, pode favorecer diálogos entre saberes construídos em bases distintas, entretanto, não se pode ter o controle do devir histórico.

Cabe ao movimento indígena redefinir os termos do diálogo entre a perspectiva ocidental/universalizante/colonial e os saberes indígenas em simetria.

\section{Referências}

ALMEIDA, M. R. M. A gente vivis de trás dos outros: processo de reorganização social Krenyê. Tese (Doutorado em Ciências Sociais). São Luís: UFMA - PPGCS, 2017.

ARAÚJO, A. V. (org.). Povos Indígenas e a Lei dos "Brancos": o direito à diferença. Brasília: Ministério da Educação, 2006.

BEGNAMI, J. B.; BURGHGRAVE, T. (orgs). Pedagogia da alternância e sustentabilidade. Orizona: UNEFAB, 2013. 
BRASIL, MINISTÉRIO DA EDUCAÇÃO. Proposta de Diretrizes para a formação de professores da educação básica em nível Superior. Brasília. 2000 .

CARDOSO DE OLIVEIRA, Roberto. $O$ índio e o mundo dos brancos. Campinas: Ed. UNICAMP, 1996.

CONSELHO NACIONAL DE EDUCAÇÃO. CÂMARA DE EDUCAÇÃO BÁSICA. Resolução CNECEB n 2/2001. Brasília.

CONSELHO NACIONAL DE EDUCAÇÃO. CÂMARA DE EDUCAÇÃO SUPERIOR. Parecer CNE/CES 492/2001. Brasília.

CONSELHO NACIONAL DE EDUCAÇÃO. Resolução CNE/CP 2/2002. Brasília. CONSELHO NACIONAL DE EDUCAÇÃO. CÂMARA DE EDUCAÇÃO SUPERIOR. Resolução CNE/CES n 9/2004. Brasília.

CUNHA, M. C. Índios no Brasil: história, direitos e cidadania. São Paulo: Claro Enigma, 2012.

DE PAULA, A. S. Processos de manutenção e avivamento linguístico; o caso do Acre. In: HORA, D.; LUCENA, R. M. Politica lingüistica na América Latina. João Pessoa: Idéia, 2008.

DE PAULA, A. S.; CUNHA, C. M. Política linguística para as línguas indígenas. In. SA JÚNIOR, L. A.; BARBOSA, T. M. N. (orgs.) Práticas discursivas e ensino de língua(gens). p. 196-217. Natal: EDUFRN, 2014.

FURTADO, M. L. S. A passos de meninos: uma análise da política educacional indigenista. Dissertação (Mestrado em Sociologia). Fortaleza: UFC, 2001.

FURTADO, M. L. S. Do outro lado da ponte: um olhar sobre a política educacional indigen(ist)a. In: Max Maranhão Piorsky. (Org.). Escolas indígenas e politicas interculturais no nordeste brasileiro. Fortaleza: Editora da UECE, 2009.

FURTADO, M. L. S. A (des)construção da multiculturalidade brasileira: uma análise do campo educacional indigenista. In: Terezinha Moreira Lima. (Org.). Desenvolvimento, poder e cultura politica. p. 103-121. São Luís: UEMA, 2006.

FURTADO, M. L. S. Aquilombamento no Maranhão: um Rio Grande de (im) possibilidades. Tese (Doutorado). Presidente Prudente: UNESP / FCT, 2012.

HOFFMANN, J. Avaliação Mediadora: Uma prática em construção da pré-escola à universidade. Porto Alegre: Editora Mediação, 2003. 
INEP. Censo Escolar da Educação Básica 2013: resumo técnico. Brasília: INEP, 2014. MINISTÉRIO DA EDUCAÇÃO. CONSELHO NACIONAL DE EDUCAÇÃO. Resolução CNE 01/2015. Brasília, 2015.

MINISTÉRIO DA EDUCAÇÃO. UNIVERSIDADE FEDERAL DA GRANDE DOURADOS. Curso de Licenciatura Indígena. Projeto Pedagógico. Grande Dourados: Mimeo, 2010.

MINISTÉRIO DA EDUCAÇÃO. UNIVERSIDADE FEDERAL DE GOIÁS. Projeto Político-Pedagógico Educação Intercultural. Goiânia: Mimeo, 2010.

PIMENTA, S. G. (org.) Saberes Pedagógicos e Atividade Docente. $2^{\mathrm{a}}$ ed. São Paulo: Cortez, 2002.

RIBEIRO, M. Pedagogia da Alternância na educação rural do/no campo: projetos em disputa. São Paulo: Educação e Pesquisa. Vol. 34. N. 1. Jan/ abr 2008. pp.27-45.

RODRIGUES, A. D. Línguas Brasileiras: para o conhecimento das línguas indígenas. São Paulo: Loyola, 1986.

RODRIGUES, A. D. Linguas indígenas: 500 anos de descobertas e perdas. DELTA, vol. 9 (1): 83-103. São Paulo, 1993.

SEKI, L. Línguas indigenas no Brasil no limiar do século XXI. Revista Impulso, $\mathrm{n}^{\circ} .27,2000$.

UNIVERSIDADE ESTADUAL DO MARANHÃO. Projeto do Curso de Licenciatura Intercultural para a Educação Básica Indígena. São Luís: Mimeo, 2015. Disponível em: $<$ https://ww2.ibge.gov.br/indigenas/indigena_censo2010.pdf $>$. Acesso em: 03 fev. 2018.

Recebido para publicação em março de 2018.

Aceito para publicação em maio de 2018. 